\title{
Postdischarge quality of care: Do age disparities exist among Department of Veterans Affairs ischemic stroke patients?
}

\begin{abstract}
Neale R. Chumbler, PhD; ${ }^{1-4 *}$ Huanguang Jia; ${ }^{5}$ Michael S. Phipps, MD ${ }^{6-7}$ Xinli Li, PhD; ${ }^{1}$ Diana Ordin, MD, MPH; ${ }^{8}$ Linda S. Williams, MD; ${ }^{1,3-4,9}$ Laura J. Myers, PhD; ${ }^{1,3,10}$ Dawn M. Bravata, MD ${ }^{1,3-4,10}$

${ }^{1}$ Department of Veterans Affairs (VA) Health Services Research and Development (HSR\&D) Center of Excellence on Implementing Evidence-Based Practice, Richard L. Roudebush VA Medical Center, Indianapolis, IN; ${ }^{2}$ Department of Sociology, Indiana University School of Liberal Arts, Indiana University Purdue University Indianapolis, Indianapolis, IN; ${ }^{3}$ VA HSR\&D Stroke Quality Enhancement Research Initiative Program, Indianapolis, IN; ${ }^{4}$ Regenstrief Institute, Indianapolis, IN; ${ }^{5}$ VA HSR\&D/Rehabilitation Research and Development Rehabilitation Outcomes Research Center Research Enhancement Award Program, Gainesville, FL; ${ }^{6}$ Department of Neurology, Yale University School of Medicine, New Haven, CT; ${ }^{7}$ VA Connecticut Healthcare System, West Haven, CT; ${ }^{8}$ VA Office of Quality and Performance, Washington, DC; Departments of ${ }^{9}$ Neurology, and ${ }^{10}$ Internal Medicine, Indiana University School of Medicine, Indianapolis, IN
\end{abstract}

\begin{abstract}
This study examined whether age disparities existed across postdischarge quality indicators (QIs) for veterans with ischemic stroke who received care at Department of Veterans Affairs medical centers (VAMCs). This retrospective cohort included a national sample of 3,196 veterans who were diagnosed with ischemic stroke and received acute and postdischarge stroke care at 127 VAMCs in fiscal year 2007 (10/1/06 through 9/30/07). Data included an assessment of postdischarge stroke QIs in the outpatient setting during the 6 mo postdischarge. The QIs included measurement of and goal achievement for (1) blood pressure, (2) serum international normalized ratio (INR) for all patients discharged on warfarin, (3) cholesterol (low-density lipoprotein [LDL]) levels, (4) serum glycosylated hemoglobin, and (5) depression treatment. The mean age for the 3,196 veterans included in this study was $67.2+/-11.3$ yr. Before risk adjustment, there were age differences in (1) depression screening/treatment, (2) blood pressure goals, and (3) LDL levels. After we adjusted for patient sociodemographic, clinical, and facility-level characteristics by using hierarchical linear mixed modeling, none of these differences remained significant but INR goals for patients discharged on warfarin differed significantly by age. After we adjusted for patient and facility characteristics, fewer age differences were found in the postdischarge stroke QIs. Clinical trial registration was not required.
\end{abstract}

Key words: adult, aged, Department of Veteran Affairs, gender, medical record review, postdischarge care, quality of health care, risk factors, stroke, stroke severity.

\section{INTRODUCTION}

Older age is one of the most common nonmodifiable risk factors for ischemic stroke [1]. Approximately two-thirds of all strokes occur in those over $65 \mathrm{yr}$ [1].

\footnotetext{
Abbreviations: $\mathrm{HbA} 1 \mathrm{C}=$ serum glycosylated hemoglobin, INR = international normalized ratio, LDL = low-density lipoprotein, $\mathrm{OR}=$ odds ratio, $\mathrm{QI}=$ quality indicator, rNIHSS = retrospective National Institutes of Health Stroke Scale, VA = Department of Veterans Affairs, VAMC = Department of Veterans Affairs medical center, VHA = Veterans Health Administration.

*Address all correspondence to Neale R. Chumbler, PhD; Department of Health Policy and Management, University of Georgia, 110 E Clayton St, Ste 300, Athens, GA 30602; 706-369-5975; fax: 706-369-5997. Email: Chumbler@uga.edu http://dx.doi.org/10.1682/JRRD.2011.08.0145
} 
However, recent research found that stroke rates are increasing in younger patients compared with older patients [2]. Robust evidence supports the application of a variety of poststroke interventions for the prevention of recurrent vascular events (e.g., hypertension management) across the spectrum of age groups [3]. Although older patients derive as much, if not more, benefit from acute stroke treatments and prevention strategies (e.g., warfarin and thrombolysis) than younger patients [4-6], some studies have found that older stroke patients are less likely to receive interventions than younger patients [7-9]. A few studies have examined age disparities in stroke management. A Canadian study found that rates of antiplatelet and warfarin for atrial fibrillation at discharge were similar across age groups [10]. On the other hand, individuals in the older age groups (60-69, 70-79, and 80 yr) were significantly more likely than their younger counterparts to be discharged with antihypertensive treatment. A separate study found that older individuals (85+ yr) were less likely to receive secondary prevention (e.g., documented measure of blood cholesterol) [11]. Using a nationally representative telephone self-report survey to explore disparities in 11 stroke secondary prevention services (e.g., serum glycosylated hemoglobin [HbA1c] measurement; serum cholesterol measurement), Ross and colleagues reported that individuals younger than 65 were less likely than those 65-79 to report receipt of recommended services (e.g., serum cholesterol measurement) [12]. Still yet a separate study found that the oldest hypertension patients, despite worse blood pressure control, were being treated less aggressively with fewer medications than their younger counterparts [13]. In sum, some previous studies have found age differences in the process of care, but whether the same differences exist in Department of Veterans Affairs (VA) stroke care is unclear.

Recent data indicate that the Veterans Health Administration (VHA) treats a sizable number of veterans with stroke in the ambulatory care setting. In the United States, approximately 7 million individuals have experienced a stroke. Each year, nearly 795,000 people experience a new or recurrent stroke. In the VHA for 2007, nearly 6,000 veterans were admitted to a VA facility with a primary discharge diagnosis of ischemic stroke and more than 61,000 unique patients had an outpatient visit with stroke listed as the primary diagnosis [2].

The VHA is the largest healthcare system in the United States and has a record of providing high-quality care; however, little data are available regarding the existence of age differences in postdischarge stroke care quality. The purpose of this study was to examine whether age differences exist in performance on postdischarge stroke care quality indicators (QIs) among VHA stroke survivors. VHA traditionally has not dealt with the frontline care of stroke victims and tends to treat stroke patients in the rehabilitation setting.

\section{METHODS}

\section{Materials and Patients}

The data were obtained from a retrospective cohort of veterans who were admitted to a VA medical center (VAMC) with an ischemic stroke during fiscal year 2007 (October 1, 2006-September 30, 2007). Medical record review was performed on a sample of 5,000 patients; the sample was constructed by including 100 percent of patients from smaller volume medical centers and an 80 percent sample from larger volume medical centers. Patients were excluded if they were admitted for elective carotid endarterectomy, admitted only for poststroke rehabilitation, initially admitted for a nonstroke condition when the ischemic stroke event occurred, or admitted to a VAMC that did not use the VHA electronic medical record system. The original cohort included 3,965 patients (from 129 VAMCs) who were eligible for at least one inpatient QI. For the current study, we excluded veterans who died in the hospital, were readmitted within $30 \mathrm{~d}$, died within $30 \mathrm{~d}$, or left the hospital against medical advice, yielding a total sample size of 3,196 patients at 128 VAMCs. Note that numbers for exclusions are not mutually exclusive.

\section{Quality Indicators}

We examined five discharge QIs. By design, eligibility for each of these QIs was restricted to patients who had received postdischarge stroke care in the outpatient setting within 6 mo. No standard protocol exists for postacute stroke care across the system. The types of procedures performed on the patients over this 6 mo period involved many factors of consideration (e.g., patient's condition including physical and mental deficits, availability and accessibility of services) and are done at the discretion of the provider. These QIs included both the measurement and achievement of the following goals: (1) blood pressure of $<140 / 90 \mathrm{~mm} \mathrm{Hg}$ for patients without 
diabetes or kidney disease and $<130 / 80 \mathrm{~mm} \mathrm{Hg}$ for patients with diabetes or kidney disease; (2) serum international normalized ratio (INR) measurement of between 2 and 3 inclusive for patients discharged on warfarin; (3) low-density lipoprotein (LDL) cholesterol $<100 \mathrm{mg} / \mathrm{dL}$ for all patients; (4) HbA1c <8 percent for patients with diabetes (or patients who had HbA1c of $7 \%$ or greater during stroke hospitalization without a previous history of diabetes); and (5) depression screening and, for those with a positive screen, appropriate management through counseling and/or pharmacologic treatment. Each of these five QIs was measured as the proportion of eligible patients in the designated age appropriately managed per QI specifications [1]. When patients had multiple outpatient visits during the 6 mo after discharge, the last measurement was selected for analysis.

\section{Independent Variable}

Patient age was based on chart review and measured in years and calculated by subtracting each patient's date of birth from the date of stroke diagnosis, then dividing by $365.25 \mathrm{~d}$. Age was classified as an ordinal variable consisting of five categories: $<55$, 55-64, 65-74, 75-84, and $\geq 85$ yr.

\section{Patient and Facility Characteristics}

The following patient characteristics were considered potential confounders and were included in the risk adjustment for the final model that examined whether age was associated with the five postdischarge QIs: sex, race, marital status, medical comorbid conditions, stroke severity, overall patient disease severity, discharge destination, prestroke residence, and admission code status. Race was classified as African American, non-Hispanic white, and all others. Marital status was coded as married versus all others. The Charlson Comorbidity score was included as a measure of medical comorbidity [14]. The retrospective National Institutes of Health Stroke Scale (rNIHSS) [15] was used as an adjustment for stroke severity and was categorized as mild (NIHSS $\leq 2$ ), moderate (NIHSS 3-9), and severe (NIHSS $\geq 10$ ). The admission modified Acute Physiology and Chronic Health Evaluation III was used to adjust for the overall patient disease severity [16]. Admission code status was classified as full code (i.e., do not resuscitate or do not intubate) versus other. Prestroke residence was classified as home versus all other. Discharge disposition was classi- fied as home versus all other settings. We also controlled for the clustering effect of the VA facilities.

\section{Statistical Analysis}

We compared patients' demographic and clinical characteristics across the five age categories by using chi-square tests for categorical variables and analysis of variance or Kruskal-Wallis tests for continuous variables. The probability values indicate a test for increasing or decreasing trends across age groups. The performance on each QI measure was compared among age groups with risk-adjustment for patient sociodemographic, clinical, and facility-level characteristics (as described) using hierarchical generalized linear modeling. All tests were two-tailed and $p<0.05$ was considered significant. All statistical analyses were performed using SAS version 9.2 (SAS Institute Inc; Cary, North Carolina).

\section{RESULTS}

Table 1 presents the characteristics of the cohort by age group. Among the 3,196 veterans, 12.2 percent were $<55 \mathrm{yr}$ of age, 35.8 percent were 55-64, 22.0 percent were $65-74,23.1$ percent were $75-84$, and 7.0 percent were $\geq 85$. Stroke severity increased substantially with age, with 5.1 percent of patients in the youngest group versus 13.5 percent in the oldest group having an rNIHSS $\geq 10(p<0.001)$.

Table 2 shows the unadjusted results for each individual postdischarge QI by age categories. Overall QI performance rates varied widely (from $33.2 \%$ for screening and treatment for depression to $61.8 \%$ for LDL goal achievement). Three QIs had significant differences between the age groups: treatment of depression was higher for veterans $<55 \mathrm{yr}$ than for older veterans $(p<$ 0.05 ) and LDL goal achievement was lower for veterans $<55 \mathrm{yr}$ than for their older counterparts $(p<0.05)$. Blood pressure goal achievement was lower for veterans 55-64 yr than for veterans 75-84 yr.

Table 3 presents the adjusted odds ratios (ORs) for postdischarge QI scores. We used the age $<55$ group as a reference category. After patient and facility characteristics were adjusted for, postdischarge INR control was substantially higher for veterans 85 yr or older than for those $<55$ yr (OR $=5.6$, 95\% confidence interval $=1.2$ 27.0, $p=0.03)$. 
JRRD, Volume 50, Number 2, 2013

Table 1.

Patients' baseline demographic and clinical characteristics.

\begin{tabular}{|c|c|c|c|c|c|c|c|}
\hline \multirow[b]{2}{*}{ Variable } & \multicolumn{6}{|c|}{ Age Group } & \multirow[b]{2}{*}{$p$-Value } \\
\hline & $\begin{array}{c}\text { Overall, } N= \\
3,196\end{array}$ & $\begin{array}{c}<55, n=389 \\
(12.2 \%)\end{array}$ & $\begin{array}{c}55-64, n= \\
1,144(35.8 \%)\end{array}$ & $\begin{array}{c}65-74, n=702 \\
(22.0 \%)\end{array}$ & $\begin{array}{c}75-84, n=739 \\
(23.1 \%)\end{array}$ & $\begin{array}{c}85+, n=222 \\
(7.0 \%)\end{array}$ & \\
\hline$\overline{\text { Age (Mean } \pm \text { SD) }}$ & $67.2 \pm 11.3$ & & & & & & \\
\hline Sex: Female (\%) & 2.6 & 5.1 & 2.4 & 2.0 & 2.2 & 2.7 & 0.02 \\
\hline Married (\%) & 43.1 & 30.3 & 38.2 & 49.0 & 50.6 & 46.9 & $<0.001$ \\
\hline Race (\%) & & & & & & & $<0.001$ \\
\hline White, Non-Hispanic & 62.1 & 47.6 & 60.4 & 64.0 & 67.8 & 71.6 & \\
\hline African American & 23.6 & 38.3 & 25.8 & 21.5 & 17.1 & 15.3 & \\
\hline Other & 14.3 & 14.1 & 13.8 & 14.5 & 15.2 & 13.1 & \\
\hline \multicolumn{8}{|l|}{ Charlson Index } \\
\hline Median (IQR) & $4(3-6)$ & & & & & & \\
\hline Mean \pm SD Score & $4.6 \pm 2.0$ & $2.6 \pm 1.5$ & $3.7 \pm 1.4$ & $4.9 \pm 1.5$ & $6.2 \pm 1.6$ & $6.8 \pm 1.4$ & $<0.001$ \\
\hline \multicolumn{8}{|l|}{ rNIHSS } \\
\hline Median (IQR) & $2(1-5)$ & & & & & & \\
\hline Mean \pm SD Score & $3.7 \pm 4.5$ & $3.2 \pm 4.1$ & $3.5 \pm 4.2$ & $3.7 \pm 4.4$ & $4.1 \pm 4.8$ & $4.7 \pm 5.5$ & $<0.001$ \\
\hline$\leq 2$ & 51.4 & 54.2 & 54.5 & 50.9 & 47.9 & 44.6 & 0.003 \\
\hline $3-9$ & 40.5 & 40.6 & 37.6 & 41.6 & 43.3 & 41.9 & \\
\hline$\geq 10$ & 8.1 & 5.1 & 8.0 & 7.6 & 8.8 & 13.5 & \\
\hline \multicolumn{8}{|l|}{ APACHE } \\
\hline Median (IQR) & $11.0(7-16)$ & & & & & & \\
\hline Mean \pm SD Score & $12.1 \pm 7.1$ & $11.0 \pm 6.5$ & $11.6 \pm 7.0$ & $12.3 \pm 7.4$ & $13.0 \pm 7.1$ & $13.5 \pm 7.4$ & $<0.001$ \\
\hline \multicolumn{8}{|c|}{ Systolic Blood Pressure, mmHg } \\
\hline Median (IQR) & $150(133-169)$ & & & & & & \\
\hline Mean \pm SD & $152.0 \pm 28.1$ & $152.5 \pm 29.3$ & $152.1 \pm 28.7$ & $152.6 \pm 28.2$ & $151.5 \pm 27.4$ & $150.2 \pm 24.5$ & 0.37 \\
\hline \multicolumn{8}{|c|}{ Diastolic Blood Pressure, mmHg } \\
\hline Median (IQR) & $82(71-93)$ & & & & & & \\
\hline Mean \pm SD & $82.7 \pm 16.9$ & $91.2 \pm 17.0$ & $85.4 \pm 16.6$ & $81.3 \pm 16.3$ & $77.2 \pm 15.5$ & $76.2 \pm 14.8$ & $<0.001$ \\
\hline \multicolumn{8}{|c|}{$\mathrm{LDL}, \mathrm{mg} / \mathrm{dL}(n=2,065)$} \\
\hline Median (IQR) & $101(77-128)$ & & & & & & \\
\hline Mean \pm SD & $105.4 \pm 42.2$ & $113.4 \pm 38.7$ & $111.7 \pm 42.9$ & $101.4 \pm 36.1$ & $95.3 \pm 35.8$ & $99.4 \pm 69.1$ & $<0.001$ \\
\hline \multicolumn{8}{|l|}{ HbA1c, \% $(n=1,103)$} \\
\hline Median (IQR) & $7.3(6.4-8.9)$ & & & & & & \\
\hline Mean \pm SD & $7.8 \pm 2.0$ & $8.9 \pm 2.5$ & $8.0 \pm 2.1$ & $7.7 \pm 2.0$ & $7.3 \pm 1.4$ & $7.2 \pm 1.6$ & $<0.001$ \\
\hline \multicolumn{8}{|l|}{ Medical History (\%) } \\
\hline Hypertension & 78.9 & 73.0 & 77.4 & 83.2 & 81.5 & 75.7 & $<0.001$ \\
\hline Diabetes & 39.5 & 33.4 & 42.5 & 44.0 & 37.6 & 26.1 & $<0.001$ \\
\hline Hyperlipidemia & 48.5 & 40.6 & 49.1 & 53.4 & 49.9 & 38.7 & $<0.001$ \\
\hline Atrial Fibrillation & 9.4 & 1.5 & 4.6 & 8.0 & 18.5 & 21.2 & $<0.001$ \\
\hline CHF & 10.6 & 5.4 & 9.5 & 9.8 & 15.4 & 11.3 & $<0.001$ \\
\hline Cancer & 1.7 & 1.3 & 1.7 & 1.4 & 2.3 & 1.8 & 0.68 \\
\hline Dementia & 7.0 & 0.8 & 1.8 & 5.3 & 15.0 & 23.9 & $<0.001$ \\
\hline Stroke & 24.6 & 16.7 & 23.7 & 27.4 & 27.5 & 24.3 & $<0.001$ \\
\hline TIA & 6.9 & 4.4 & 6.6 & 7.1 & 7.9 & 9.0 & 0.16 \\
\hline Carotid Stenosis & 4.9 & 2.1 & 3.6 & 5.4 & 8.1 & 3.6 & $<0.001$ \\
\hline CAD & 26.7 & 13.1 & 23.9 & 29.8 & 33.6 & 32.0 & $<0.001$ \\
\hline MI & 10.0 & 6.7 & 9.0 & 12.7 & 10.8 & 10.4 & 0.02 \\
\hline Depression & 16.6 & 19.0 & 20.1 & 13.4 & 13.9 & 13.5 & $<0.001$ \\
\hline
\end{tabular}


Table 1. (cont)

Patients' baseline demographic and clinical characteristics.

\begin{tabular}{|c|c|c|c|c|c|c|c|}
\hline \multirow[b]{2}{*}{ Variable } & \multicolumn{6}{|c|}{ Age Group } & \multirow[b]{2}{*}{$p$-Value } \\
\hline & $\begin{array}{c}\text { Overall, } N= \\
3,196\end{array}$ & $\begin{array}{c}<55, n=389 \\
(12.2 \%)\end{array}$ & $\begin{array}{c}55-64, n= \\
1,144(35.8 \%)\end{array}$ & $\begin{array}{c}65-74, n=702 \\
(22.0 \%)\end{array}$ & $\begin{array}{c}75-84, n=739 \\
(23.1 \%)\end{array}$ & $\begin{array}{c}85+, n=222 \\
(7.0 \%)\end{array}$ & \\
\hline Smoking History & 36.1 & 63.5 & 50.3 & 30.1 & 14.6 & 5.0 & $<0.001$ \\
\hline Comfort Measure & 0.5 & 0.3 & 0.3 & 0.4 & 0.7 & 2.3 & 0.02 \\
\hline DNR/DNI & 9.2 & 4.1 & 5.2 & 8.7 & 13.9 & 24.8 & $<0.001$ \\
\hline Preambulatory & 94.8 & 98.2 & 96.5 & 96.2 & 91.3 & 88.3 & $<0.001$ \\
\hline $\begin{array}{l}\text { Discharge Disposition, } \\
\text { Home (\%) }\end{array}$ & 65.4 & 79.7 & 71.2 & 65.8 & 57.0 & 37.8 & $<0.001$ \\
\hline $\begin{array}{l}\text { Outpatient Visits } \\
\text { (Mean } \pm \text { SD) }\end{array}$ & $2.9(2.7)$ & $3.4(3.1)$ & $3.0(2.7)$ & $3.0(2.5)$ & $2.8(2.7)$ & $2.1(2.5)$ & $<0.001$ \\
\hline
\end{tabular}

Table 2.

6 mo postdischarge quality indicators (QIs) for veterans with ischemic stroke by age group (unadjusted). Data shown as $n$ (\%).

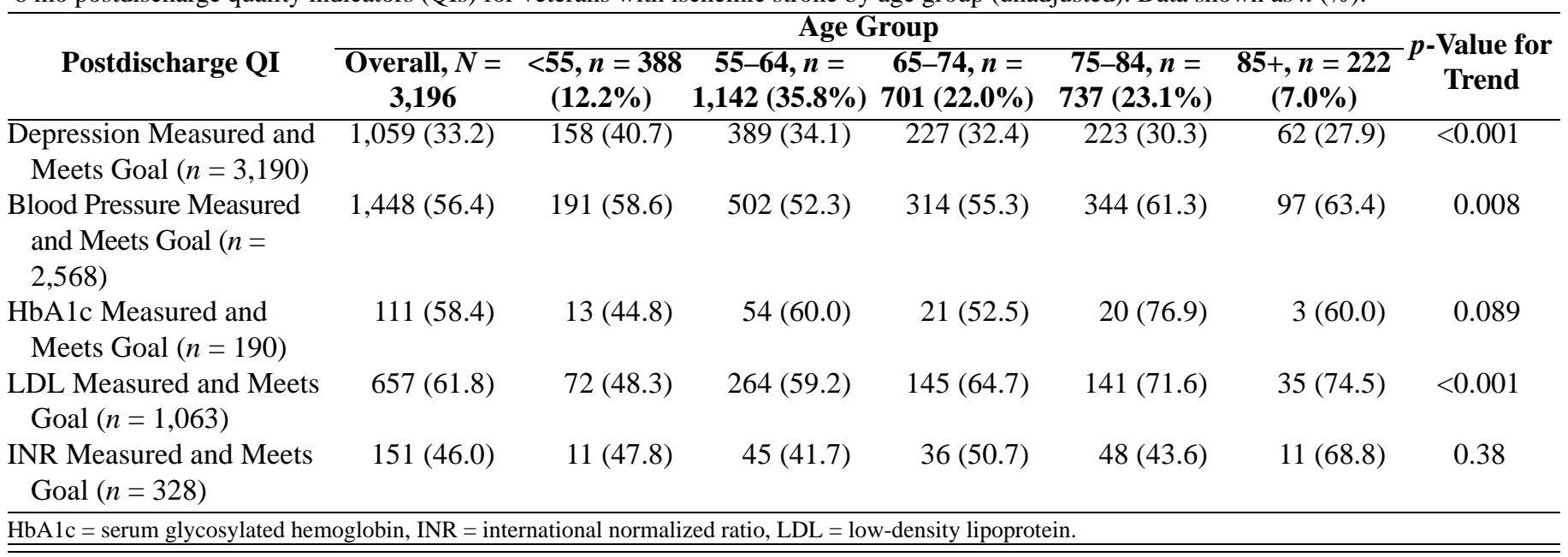

\section{DISCUSSION}

In this nationally representative sample of VHA ischemic stroke survivors, several age-related differences in postdischarge QIs were found in unadjusted analysis; however, after adjustment for key sociodemographic, clinical, and facility-level characteristics, only one difference in performance on postdischarge QIs remained. Postdischarge INR control was substantially higher for veterans $85 \mathrm{yr}$ of age and older. Neither the unadjusted nor the adjusted results demonstrated a consistent decrement in quality with increasing age, but rather some pro- cesses of care were provided more often to older patients (i.e., LDL goal achievement) whereas other processes were provided more often to younger patients (i.e., treatment of depression and blood pressure goal achievement). The age difference for postdischarge INR control was inconsistent with previous studies, which found that stroke patients with atrial fibrillation discharged on warfarin either did not differ by age $[10,17]$ or postdischarge INR control was lower in older patients (aged 80 and older) than younger patients [1]. Because the number of patients in the study who had atrial fibrillation and were eligible for this QI in the age 80 and older category was 
JRRD, Volume 50, Number 2, 2013

Table 3.

Adjusted odds ratio (OR) for postdischarge quality indicators (QIs) for veterans with ischemic stroke.

\begin{tabular}{|c|c|c|}
\hline \multirow{2}{*}{ Postdischarge QI } & \multicolumn{2}{|c|}{ Adjusted } \\
\hline & OR (95\% CI) & $p$-Value \\
\hline \multicolumn{3}{|l|}{ Depression Measured and Meets Goal } \\
\hline \multicolumn{3}{|l|}{ Age } \\
\hline$<55$ & ref & \\
\hline $55-64$ & $0.8(0.6-1.1)$ & 0.17 \\
\hline $65-74$ & $0.9(0.6-1.2)$ & 0.30 \\
\hline $75-84$ & $0.9(0.7-1.3)$ & 0.67 \\
\hline $85+$ & $1.0(0.6-1.6)$ & 0.98 \\
\hline \multicolumn{3}{|l|}{ Blood Pressures Measured and Meet Goal } \\
\hline \multicolumn{3}{|l|}{ Age } \\
\hline$<55$ & ref & \\
\hline $55-64$ & $0.8(0.6-1.0)$ & 0.09 \\
\hline $65-74$ & $1.0(0.7-1.3)$ & 0.80 \\
\hline $75-84$ & $1.3(0.9-1.8)$ & 0.14 \\
\hline $85+$ & $1.4(0.9-2.3)$ & 0.14 \\
\hline \multicolumn{3}{|l|}{ LDL Measured and Meets Goal } \\
\hline \multicolumn{3}{|l|}{ Age } \\
\hline$<55$ & ref & \\
\hline $55-64$ & $1.2(0.8-1.8)$ & 0.31 \\
\hline $65-74$ & $1.4(0.8-2.2)$ & 0.23 \\
\hline 75-84 & $1.6(0.9-2.8)$ & 0.11 \\
\hline $85+$ & $1.5(0.6-3.5)$ & 0.34 \\
\hline \multicolumn{3}{|l|}{ HbA1c Measured and Meets Goal } \\
\hline \multicolumn{3}{|l|}{ Age } \\
\hline$<55$ & ref & \\
\hline $55-64$ & $1.7(0.5-5.5)$ & 0.36 \\
\hline $65-74$ & $1.0(0.2-4.4)$ & 0.95 \\
\hline 75-84 & $3.9(0.7-22.4)$ & 0.12 \\
\hline $85+$ & $0.4(0.0-8.7)$ & 0.59 \\
\hline \multicolumn{3}{|l|}{ INR Measured and Meets Goal } \\
\hline \multicolumn{3}{|l|}{ Age } \\
\hline$<55$ & ref & \\
\hline $55-64$ & $1.1(0.4-2.8)$ & 0.90 \\
\hline $65-74$ & $2.1(0.7-6.1)$ & 0.18 \\
\hline 75-84 & $1.7(0.6-5.1)$ & 0.35 \\
\hline $85+$ & $5.6(1.2-27.0)$ & 0.03 \\
\hline
\end{tabular}

so small, this result may be due to chance. It is also possible that older people on warfarin were more carefully monitored, given the concern for bleeding. Even though our study was not designed to evaluate the appropriate- ness of anticoagulation decision making, our findings suggest follow-up questions that future research should explore. Future research should investigate the association between the frequency of INR monitoring and outcomes 
such as readmissions for either thromboembolic events (e.g., stroke) or hemorrhagic events (e.g., gastrointestinal bleeds).

Some study limitations deserve mention. First, as a result of the clinical context of the VHA, the study sample of ischemic stroke patients was overwhelmingly male (97.5\%) and may not be generalizable outside the VHA. Second, we had no available data on use of non-VHA care; Medicare-eligible veterans, most of whom were $\geq 65$, may have been more likely than younger veterans to have received some of their care outside the VA. As a previous report indicated, 70 percent of VHA stroke patients also received some poststroke care from nonVHA healthcare programs, including 60 percent VHAMedicare dual system users, 3 percent VHA-Medicaid dual system users, and 7 percent VHA-Medicare-Medicaid triple system users [18]. Future research should consider VHA stroke patients' service use beyond the VHA system in order to obtain a more comprehensive evaluation of stroke patients. Third, adherence to medical appointments and medications may be associated with outcomes of these interventions. As a result of the limitations of the data set, we were unable to control for patient adherence (e.g., the extent to which patients were able to keep their regularly scheduled appointments) in the multivariate models. Future studies should further explore the association between the visits and adherence between discharge and 6 mo. Future research should also investigate the extent to which adherence to visits is associated with patient age, which, in turn, could affect whether or not patients received postdischarge stroke care in the outpatient setting. Fourth, VHA does not deal with the frontline care of most stroke victims. Such care tends to occur in each community's emergency medical services and trauma care system. After stabilization, the patient is transferred to the VHA facility nearby. This lack of first contact for many veterans with stroke and possible transfer trauma could significantly affect the outcomes of these patients' recoveries. Future research should investigate the extent to which this transition of care impacts future VHA care, especially in a rehabilitation setting.

Despite these limitations, our study makes an important contribution to the literature in at least two ways. First, our study had an admission rNIHSS on all study participants, enabling the adjustment for stroke severity as a key covariate in understanding the relationship between age and quality of care. In the present study, patient stroke severity and comorbidities were the two variables that consistently accounted for the differences between the unadjusted and adjusted findings. Previous studies either did not control for stroke severity [12] or did not have stroke severity uniformly available and consequently could not adjust for stroke severity in the entire cohort [1]. Second, in contrast to some previous studies that depended exclusively on patients' self-report [4], the present study included actual clinical data collected during medical encounters and abstracted from medical charts.

\section{CONCLUSIONS}

In sum, after we adjusted for a comprehensive set of patient and facility characteristics, overall postdischarge quality for ischemic stroke in VHA did not vary consistently by age. However, the few differences that emerged from this study should encourage the VHA to maintain awareness about possible age disparities. Stroke management should be guided by the best clinical evidence and guidelines irrespective of age.

\section{ACKNOWLEDGMENTS}

\section{Author Contributions:}

Study concept and design: N. R. Chumbler, H. Jia, M. S. Phipps, X. Li, D. Ordin, L. S. Williams, D. M. Bravata.

Acquisition of data: D. M. Bravata, D. Ordin.

Analysis and interpretation of data: N. R. Chumbler, H. Jia,

M. S. Phipps, X. Li, D. Ordin, L. S. Williams, L. J. Myers,

D. M. Bravata.

Drafting of manuscript: N. R. Chumbler.

Manuscript revision: N. R. Chumbler, H. Jia, M.S. Phipps, X. Li, D. Ordin, L. S. Williams, L. J. Myers, D. M. Bravata.

Regulatory oversight: D. M. Bravata.

Financial Disclosures: The authors have declared that no competing interests exist.

Funding/Support: This material was based on work supported by the VA, VHA, Office of Quality and Performance, and Health Services Research and Development Service Quality Enhancement Research Initiative (grant RRP 09-184).

Additional Contributions: An earlier version of this article was presented at the 2011 Annual Meeting of the American Sociological Association, Las Vegas, Nevada. Dr. Chumbler is now with the Department of Health Policy and Management, College of Public Health, University of Georgia. Dr. Phipps is now with the Department of Neurology, University of Connecticut/Hartford Hospital, and VA Connecticut Healthcare System. 
Institutional Review: This study was approved by the institutional review board at Indiana University and the Research and Development Committee at the Roudebush VAMC in Indianapolis, Indiana.

Disclaimer: The views expressed in this article are those of the authors and do not necessarily represent the views of the VA.

\section{REFERENCES}

1. Fonarow GC, Reeves MJ, Zhao X, Olson DM, Smith EE, Saver JL, Schwamm LH; Get With the Guidelines-Stroke Steering Committee and Investigators. Age-related differences in characteristics, performance measures, treatment trends, and outcomes in patients with ischemic stroke. Circulation. 2010;121(7):879-91. [PMID:20142445]

http://dx.doi.org/10.1161/CIRCULATIONAHA.109.892497

2. Roger VL, Go AS, Lloyd-Jones DM, Benjamin EJ, Berry JD, Borden WB, Bravata DM, Dai S, Ford ES, Fox CS, Fullerton HJ, Gillespie C, Hailpern SM, Heit JA, Howard VJ, Kissela BM, Kittner SJ, Lackland DT, Lichtman JH, Lisabeth LD, Makuc DM, Marcus GM, Marelli A, Matchar DB, Moy CS, Mozaffarian D, Mussolino ME, Nichol G, Paynter NP, Soliman EZ, Sorlie PD, Sotoodehnia N, Turan TN, Virani SS, Wong ND, Woo D, Turner MB; American Heart Association Statistics Committee and Stroke Statistics Subcommittee. Heart disease and stroke statistics2012 update: a report from the American Heart Association. Circulation. 2012;125(1):e2-220. [PMID:22179539] http://dx.doi.org/10.1161/CIR.0b013e31823ac046

3. Sacco RL, Adams R, Albers G, Alberts MJ, Benavente O, Furie K, Goldstein LB, Gorelick P, Halperin J, Harbaugh R, Johnston SC, Katzan I, Kelly-Hayes M, Kenton EJ, Marks M, Schwamm LH, Tomsick T; American Heart Association/American Stroke Association Council on Stroke; Council on Cardiovascular Radiology and Intervention; American Academy of Neurology. Guidelines for prevention of stroke in patients with ischemic stroke or transient ischemic attack: a statement for healthcare professionals from the American Heart Association/American Stroke Association Council on Stroke: co-sponsored by the Council on Cardiovascular Radiology and Intervention: the American Academy of Neurology affirms the value of this guideline. Circulation. 2006;113(10):e409-49. [PMID:16534023]

4. Gómez-Choco M, Obach V, Urra X, Amaro S, Cervera A, Vargas M, Chamorro A. The response to IV rt-PA in very old stroke patients. Eur J Neurol. 2008;15(3):253-56. [PMID:18190509] http://dx.doi.org/10.1111/j.1468-1331.2007.02042.x

5. Glader EL, Sjölander M, Eriksson M, Lundberg M. Persistent use of secondary preventive drugs declines rapidly during the first 2 years after stroke. Stroke. 2010;41(2): 397-401. [PMID:20075360]

http://dx.doi.org/10.1161/STROKEAHA.109.566950

6. Ford GA, Ahmed N, Azevedo E, Grond M, Larrue V, Lindsberg PJ, Toni D, Wahlgren N. Intravenous alteplase for stroke in those older than 80 years old. Stroke. 2010;41(11):2568-74. [PMID:20930163]

http://dx.doi.org/10.1161/STROKEAHA.110.581884

7. Olindo S, Cabre P, Deschamps R, Chatot-Henry C, RenéCorail P, Fournerie P, Saint-Vil M, May F, Smadja D. Acute stroke in the very elderly: epidemiological features, stroke subtypes, management, and outcome in Martinique, French West Indies. Stroke. 2003;34(7):1593-97. [PMID:12829873] http://dx.doi.org/10.1161/01.STR.0000077924.71088.02

8. Lau E, Bungard TJ, Tsuyuki RT. Stroke prophylaxis in institutionalized elderly patients with atrial fibrillation. J Am Geriatr Soc. 2004;52(3):428-33. [PMID:14962160] http://dx.doi.org/10.1111/j.1532-5415.2004.52117.x

9. Tabereaux PB, Brass LM, Concato J, Bravata DM. Hospital admissions for stroke among the very old in the USA. Neuroepidemiology. 2008;31(2):93-99. [PMID:18645263] http://dx.doi.org/10.1159/000146250

10. Saposnik G, Black SE, Hakim A, Fang J, Tu JV, Kapral $\mathrm{MK}$; Investigators of the Registry of the Canadian Stroke Network (RCSN); Stroke Outcomes Research Canada (SORCan) Working Group. Age disparities in stroke quality of care and delivery of health services. Stroke. 2009;40(10):3328-35. [PMID:19696418] http://dx.doi.org/10.1161/STROKEAHA.109.558759

11. Rudd AG, Hoffman A, Down C, Pearson M, Lowe D. Access to stroke care in England, Wales and Northern Ireland: the effect of age, gender and weekend admission. Age Ageing. 2007;36(3):247-55. [PMID:17360793] http://dx.doi.org/10.1093/ageing/afm007

12. Ross JS, Halm EA, Bravata DM. Use of stroke secondary prevention services: are there disparities in care? Stroke. 2009;40(5):1811-19. [PMID:19265044] http://dx.doi.org/10.1161/STROKEAHA.108.539619

13. Borzecki AM, Glickman ME, Kader B, Berlowitz DR. The effect of age on hypertension control and management. Am J Hypertens. 2006;19(5):520-27. [PMID:16647627] http://dx.doi.org/10.1016/j.amjhyper.2005.10.022

14. Charlson ME, Pompei P, Ales KL, MacKenzie CR. A new method of classifying prognostic comorbidity in longitudinal studies: development and validation. J Chronic Dis. 1987; 40(5):373-83. [PMID:3558716] http://dx.doi.org/10.1016/0021-9681(87)90171-8

15. Williams LS, Yilmaz EY, Lopez-Yunez AM. Retrospective assessment of initial stroke severity with the NIH Stroke Scale. Stroke. 2000;31(4):858-62. [PMID:10753988] http://dx.doi.org/10.1161/01.STR.31.4.858 
16. Knaus WA, Wagner DP, Draper EA, Zimmerman JE, Bergner M, Bastos PG, Sirio CA, Murphy DJ, Lotring T, Damiano A, Harrell FE. The APACHE III prognostic system. Risk prediction of hospital mortality for critically ill hospitalized adults. Chest. 1991;100(6):1619-36. [PMID:1959406] http://dx.doi.org/10.1378/chest.100.6.1619

17. Gladstone DJ, Bui E, Fang J, Laupacis A, Lindsay MP, Tu JV, Silver FL, Kapral MK. Potentially preventable strokes in high-risk patients with atrial fibrillation who are not adequately anticoagulated. Stroke. 2009;40(1):235-40. [PMID:18757287] http://dx.doi.org/10.1161/STROKEAHA.108.516344

18. Jia H, Zheng YE, Cowper DC, Wu SS, Vogel BW, Duncan PW, Reker D. How veterans use stroke services in the VA and beyond. Fed Pract. 2006;23:21-24.
Submitted for publication August 17, 2011. Accepted in revised form June 21, 2012.

This article and any supplementary material should be cited as follows:

Chumbler NR, Jia H, Phipps MS, Li X, Ordin D, Williams LS, Myers LJ, Bravata DM. Postdischarge quality of care: Do age disparities exist among Department of Veterans Affairs ischemic stroke patients? J Rehabil Res Dev. 2013;50(2):263-72.

http://dx.doi.org/10.1682/JRRD.2011.08.0145

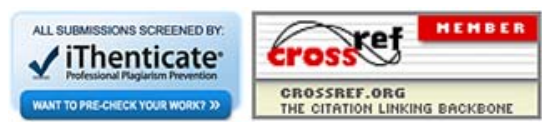


